in either field of application to be able to learn about developments in the other's field. One of the lessons to be learnt is how much of the progress that has been made depended, and still depends, on the extent to which the process is wanted-and to what extent the want is represented in terms of willingness to pay for the resultant product. S. C. Tease, for example, ends his account of progress in the United States with the positive remark that continuous food freeze-drying "will be provided in the United States upon development of specific requirement justification". This author pays a well-merited tribute to the Ministry of Agriculture, Fisheries and Food's Research Establishment at Aberdeen where, until it elosed in 1961, pioneer work was done on the accelerated freezedrying (A.F.D.) process.

Adequate attention is directed to the importance of pretreatment and subsequent storage of the processed material, U. Hackenburg, in his paper on the basic principles, giving equal prominence to the three phases. Audrey Smith contributes a most fascinating and readable article on low-temperature biology under the heading "Some Problems in Supercooling and Freezing Living Cells, Tissues and Organisms", in which she remarks that "a study of proteins in the nucleus, the cytoplasm and the external membranes of the mammalian cells after freezing under different conditions would be a reward. ing task for any biochemist competent to undertake it". Those who know the work of the biochemists at Torry Research Station on the tissues of fishes will appreciate how justified this comment is. This work is briefly mentioned by J. Kuprianoff. (If justice to this and other outstanding research on the freezing of tissues has been overlooked, it is entirely due to the failure of the publishers to provide an index. It is incomprehensible that in a book of this size, potential value and importance should not be indexed. I am tempted to recommend, on those grounds, that the book should not be purchased, but that would be treating the contributors to a fate they do not deserve.) It is possible that somewhere in the text Altmann, who in 1890 introduced the process as a histological technique, is mentioned, but it would be a long and arduous task to discover whether or not this is so.

Freeze-drying is a happy hunting-ground for the physieist, and several of the articles are devoted to problems of heat and mass transfer during the freezing, sublimation and rehydration stages. That these are not, however, merely theoretical exercises is amply brought out in their interpretation in technological practice. Not only are efficient cycles necessary in commercial design and opera. tion, but they are also often fundamental to success in preserving functional properties in biological material. This principle is well illustrated in many fields-the preparation of viruses, bacterial cultures, vaccines, plasma, enzymes and tissue banks. L. Rey, the editor, both introduces and concludes the volume with admirable essays on the present state and the future prospects of the art of lyophilization.

E. C. BAte-SMith

\section{GAS CHROMATOGRAPHY IN MEDICINE}

\section{Biomedical Applications of Gas Chromatography}

Edited by Herman A. Szymanski. (Based on Lectures presented during the Fifth Annual Gas Chromatography Institute at Canisius College, Buffalo, New York, 1963.) Pp. 324. (New York: Plenum Press, 1964.) 12.50 dollars.

A $\mathrm{N}$ introductory chapter by Dr. H. A. Szymanski is A intended to sketch briefly the basic theory of gas chromatography which is taken for granted by the authors of the main papers in Biomedical Applications of Gas Chromatography. This treatment is, however, rather too skimpy to be anything but confusing to the tyro, while it is doubtful whether it is likely to be required by those who will benefit most from this publication, that is, workers already engaged in similar fields.

The first review by Fales and Pisano (49 pages, 109 references) deals with amines, alkaloids and amino-acids, giving details for the extraction and clean-up of biological samples and choice of column packing and temperature. Chromatographic difficulties encountered with these compounds and their volatile derivatives are discussed, with emphasis on practicalities, several illustrative tracings are included. VandenHeuvel and Horning (63 pages, 116 references) discuss the separation, identification and estimation of steroids, the sections on quantitation, derivative preparation, and radioactive determinations being particularly valuable; a useful review of some practical applications is also included.

A comparatively short chapter on the gas chromatography of bile acids by Sjöval (19 pages, 32 references) summarizes the retention times of various substituted methyl cholanates on columns of different stationary phases; some identification and quantitative procedures are also mentioned. Carbohydrates are reviewed by Wells, Sweeley and Bentley (57 pages, 57 references), who predict that gas chromatography will rapidly become a routine method for the analysis of these and related compounds. The section describing the clinical and biochemical applications of gas chromatography is noteworthy and includes serum glucose determinations, galactosaemia diagnosis, sugar phosphate metabolism studies and quantitative radioactivity measurements.

An essentially practical paper by Williams and Sweeley (47 pages, 82 references) on urinary aromatic acids includes details of the preparation of volatile derivatives and infrared identification of compounds trapped from the effluent gas stream. The properties of thirty-two individual acids are catalogued and diagnostic applications to congenital diseases and tumour secretions are well illustrated. A chapter reviewing the gas chromatographic analysis of fatty acids and their derivatives by Supina (37 pages) lists 311 references, but gives little comment on their content. The final paper by Lowe and Beckham (18 pages, 30 references) describes procedures for the determination of volatile organic anaesthetics in blood samples.

This volume is claimed to be ". . . a thorough résumé of present-day applications of gas chromatography to biomedical analysis . . a a primer in this field and a useful handbook ...". These claims are well justified, and the comparative speed with which this volume has been published is to be welcomed; frequently such lectures enter a limbo from which few return. This very speed, however, appears to have had an unfortunate effect on the presentation of this useful information; the type-face is poor and spacing of letters and words is very uneven, thus impeding fluent reading, while printing errors are not infrequent. These faults apart, the book is a 'must' for libraries of laboratories dealing with any biochemical aspects of gas chromatography.

D. C. Aвво'тT

\section{DRUGS WHICH AFFECT THE STATE OF THE MIND}

Psychopharmacological Agents, Vol. I

Edited by Maxwell Gordon. (Medicinal Chemistry: a Series of Monographs, Vol. 4.) Pp. xvi +678 . (New York: Academic Press, Inc.; London: Academic Press, Inc. (London), Ltd., 1964.) $168 s$.

HE development during the past ten years of a large number of psychoactive drugs, some of which are frequently referred to only by a manufacturer's reference number, has created a need for a compendium of the drugs which have an effect on the state of the mind. Maxwell Gordon has edited an excellent review of the 